\title{
ВЫДЕЛЕНИЕ И ХАРАКТЕРИСТИКА АНТИГРИБНЫХ МЕТАБОЛИТОВ ШТАММОВ Bacillus subtilis BZR 336g И Bacillus subtilis BZR 517 МОДИФИЦИРОВАННЫМ МЕТОДОМ БИОАВТОГРАФИИ*
}

\author{
Т.М. СИДОРОВА, А.М. АСАТУРОВА, А.И. ХОМЯК, Н.С. ТОМАШЕВИЧ
}

Способность Bacillus subtilis продуцировать разнообразные по структуре и свойствам биологически активные метаболиты в значительной степени обусловливает ее фунгицидный эффект в отношении особо опасных фитопатогенных грибов. В настоящей работе из культуральной жидкости штаммов B. subtilis BZR 336g и BZR 517 впервые выделены антигрибные метаболиты, подавляющие развитие вредоносных фитопатогенных грибов, изучены свойства и химическая структура этих соединений с использованием оригинальных аналитических подходов. Целью работы было обнаружение, описание и количественная оценка антифунгальной активности метаболитов у двух штаммов Bacillus subtilis - перспективных продуцентов биофунгицидов. Используемый нами методический подход включал очистку бактериальных метаболитов экстракцией этилацетатом, разделение методом тонкослойной хроматографии (ТСX) на пластинах с силикагелем с УФвизуализацией $(\lambda=366$ нм), применение детектирующих реактивов, спектроскопию и биоавтографию. Модификация метода биоавтографии заключалась в использовании фитопатогенные грибы - возбудители вредоносных заболеваний сельскохозяйственных культур Fusarium oxysporum var. orthoceras BZRP1 и Alternaria sp. BZRP8 в качестве тест-объектов. Эксперименты выявили способность исследуемых штаммов $B$. subtilis накапливать комплекс активных метаболитов, проявляющих антигрибной эффект от фунгистатического до фунгицидного. Антигрибные соединения двух штаммов различались по подвижности при хроматографическом разделении и по характеру свечения в УФ-свете. Степень их воздействия на рост гриба также была различной. У штамма B. subtilis BZR 336g на хроматограмме обнаружены две наиболее выраженные зоны задержки роста F. oxysporum var. orthoceras BZRP1 с Rf 0,39 и 0,96. Значительное подавление роста Alternaria sp. BZRP8 также наблюдалось в двух зонах (Rf 0,42 и 0,96). Штамм B. subtilis BZR 517 синтезировал метаболиты, фунгитоксичные по отношению к $F$. oxysporum var. orthoceras BZRP1 (зоны с Rf 0,42; 0,84; 0,92; 0,96) и к грибу Alternaria sp. BZRP8 (зоны с Rf 0,42 и 0,96). Известно, что, помимо прямого действия, сурфактины и фенгицины $B$. subtilis предотвращают адгезию конкурентных микробов на растении. При опрыскивании пластин дистиллированной водой мы выявили несмачиваемые (гидрофобные) зоны, соответствующие компонентам, которые могут способствовать усилению антагонистических свойств $\boldsymbol{B}$. subtilis. Использование детектирующих реагентов позволило выявить ароматические амины, фенолы, фенольные стероиды, метилгидразины. Слабое окрашивание исследованных метаболитов нингидрином, а также отсутствие характерного осадка при подкислении культуральной жидкости и добавлении сульфата аммония может свидетельствовать о присутствии незначительных количеств аминокислот и пептидов. У метаболитов пики поглощения находились в области $\lambda=205-217$ нм, что может служить косвенным доказательством присутствия полиеновых структур. Поскольку детектирующие реактивы указывали на наличие разнообразных фенольных производных, а по данным многих исследователей активные штаммы при взаимодействии с фитопатогеном продуцируют гидролитические ферменты, можно предположить, что механизм действия метаболитов у изученных штаммов заключается в гидролизе фенольных соединений. В результате могут освобождаться активные групाы фенолов, что способствует усилению антигрибной активности синтезируемых метаболитов за счет воздействия как на клеточные стенки, так и на другие структуры клетки фитопатогенного гриба.

Ключевые слова: Bacillus subtilis, микробиологические препараты, антигрибные метаболиты, фунгитоксичность,тонкослойная хроматография, биоавтография, детектирующие реактивы, фенольные соединения, полиеновые структуры.

Сенная палочка (Bacillus subtilis) продуцирует разнообразные антимикробные метаболиты: липопептиды, полипептиды, ферменты, непептидные соединения (1-3), что в значительной степени обусловливает ее фунгицидный эффект в отношении особо опасных фитопатогенных грибов. Наиболее подробно изучены структура и механизм действия липопептидных фунгицидов, к которым относят активные пептиды из семейств итуринов, сурфактинов, фенгицинов $(4,5)$. Доказано, что синтез липопеп-

* Исследования выполнены согласно государственному заданию № 075-00376-19-00 Министерства науки и высшего образования РФ в рамках НИР по теме № 0686-2019-0013. 
тидов B. subtilis играет ключевую роль в подавлении фитопатогенов в природных условиях, при этом продукция итуринов и фенгицинов определяется присутствием фитопатогенов в окружающей среде. Высокая эффективность против мицелиальных грибов связана со способностью метаболитов $B$. subtilis влиять на мембраны посредством взаимодействия с эргостеролом, при этом происходит образование пор с последующим выходом одновалентных катионов из клеток, которые в связи с этим лизируются (5, 6). Для липопептидов из разных семейств специфические механизмы образования пор различны (7). Как правило, штаммы бактерий с высоким содержанием липопептидных антибиотиков обладают более высокой антагонистической активностью и широким спектром действия.

С другой стороны, растительные полисахариды стимулируют образование сурфактина, продуцируемого в первые часы взаимодействия бацилл с тканями корней $(8,9)$. Фунгицидную активность связывают также с наличием у бацилл поверхностно-активных веществ, которые представляют собой амфипатические молекулы с полярными и гидрофобными участками (10). Сурфактины относятся к наиболее эффективным биосурфактантам - поверхностно-активным веществам биологического происхождения. Имея сходную с итуринами структуру и антагонистические свойства, молекулы сурфактинов, в отличие от итуринов, содержат аминокислоты с гидрофобными радикалами и $\beta$-гидроксилированной жирной кислотой (11). Помимо прямого действия, сурфактины и фенгицины B. subtilis предотвращают адгезию конкурентных микробов и могут индуцировать в растениях системную устойчивость к патогенам и неблагоприятным абиотическим факторам (12). Интересно, что липопептидные антибиотики могут восприниматься клетками растений как сигнал инициации защитных механизмов, то есть быть элиситорами (13). Показано, что сурфактины и фенгицины как элиситоры иммунного ответа растения-хозяина обеспечивают значительную индукцию защитной реакции фасоли против возбудителя серой гнили Botrytis cinerea (14).

В настоящей работе у штаммов Bacillus subtilis BZR 336g и BZR 517 впервые обнаружены метаболиты, подавляющие развитие вредоносных фитопатогенных грибов. С использованием оригинальных аналитических методов и подходов определены свойства и химическая структура выявленных соединений. Полученные результаты дают основание рассматривать оба исследованных штамма в качестве потенциальных продуцентов биофунгицидов.

Целью работы было выделение, изучение химической структуры и количественная оценка антифунгальной активности метаболитов, выделяемых в культуральную жидкость, у двух перспективных штаммов B. subtilis.

Методика. В работе использовали штаммы - продуценты опытных образцов биопрепаратов B. subtilis BZR 336g и BZR 517 (15-17), а также культуры фитопатогенных грибов Fusarium oxysporum var. orthoceras BZRP1 (возбудитель корневой гнили зерновых и масличных культур) и Alternaria sp. BZRP8 (возбудитель альтернариоза плодовых культур) из коллекций Всероссийского НИИ биологической защиты растений (ВНИИБЗР).

Жидкую культуру биофунгицида на основе бактериальных штаммов получали методом периодического культивирования в термостатированных системах New Brunswick Scientific («Excella E25», США) в течение 48 ч при 180 об/мин. Состав питательной среды и условия культивирования относятся к объектам коммерческой тайны ФГБНУ ВНИИБЗР (приказ № 42-п от 28 ноября 2012 года). После завершения культивирования жидкую культуру B. subtilis центрифугировали 20 мин при 12000 g, надо- 
садочную жидкость экстрагировали в течение 1 ч тремя объемами этилацетата. Этилацетатный экстракт упаривали, сухой остаток растворяли в минимальном количестве этилацетата и анализировали методом восходящей тонкослойной хроматографии (ТСХ) на пластинах $20 \times 20$ см с модифицированным силикагелем Kieselgel 60 («Merck», Германия), толщина слоя 2 мм, система растворителей этилацетат:этанол:вода (40:15:15). После просмотра под УФ-светом при $\lambda=366$ нм и удаления следов растворителей ТСХ-пластины пропитывали картофельно-глюкозной питательной средой, затем - суспензией пропагул тестового гриба и помещали на 48-50 ч во влажную камеру при температуре $24{ }^{\circ} \mathrm{C}$ для Alternaria sp. BZRP8 и $28{ }^{\circ} \mathrm{C}$ - для $F$. oxysporum var. orthoceras BZRP1. О локализации активных компонентов судили по формированию зон отсутствия либо задержки роста гриба $(18,19)$.

Для дальнейшего изучения активных компонентов культуральной жидкости необходимое количество этилацетатного экстракта разделяли с помощью ТСХ, как описано выше. Зоны, соответствующие активным антигрибным соединениям, счищали и элюировали этилацетатом. Для качественного анализа элюатов использовали специфические детектирующие реактивы (19). Спектры поглощения активных фракций метаболитов штаммов B. subtilis BZR 336g и BZR 517 определяли при $\lambda=200-400$ нм, используя спектрофотометр SmartSpec Plus («Bio-Rad», США).

Результаты. При просмотре ТСХ-пластин под УФ 366 светом у обоих штаммов $B$. subtilis обнаружили значительный набор продуцируемых метаболитов, которые различались по хроматографической подвижности и характеру свечения (рис., А). При этом наблюдаемые паттерны у штаммов разнились.

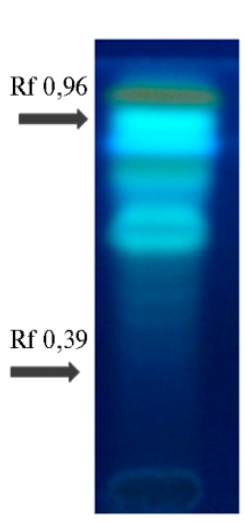

1

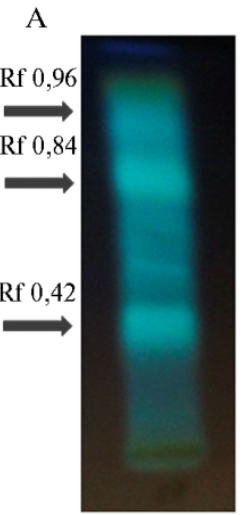

2

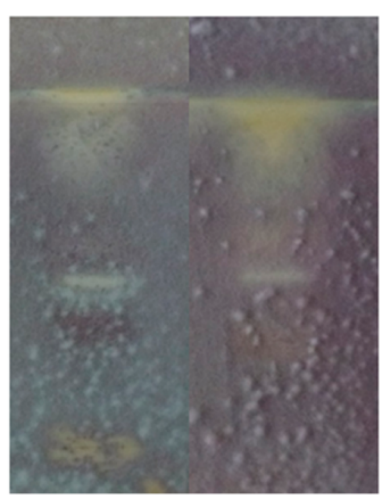

2
Б

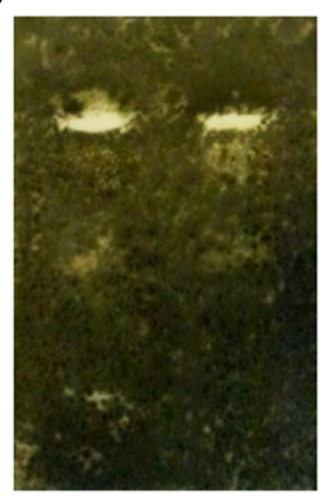

1

2

Результаты тонкослойной хроматографии (А, свечение в УФ 366 -свете) и биоавтограммы (Б, слева с тест-культурой Fusarium oxysporum var. orthoceras BZRP1, справа - с Alternaria sp. BZRP8) этилацетатных экстрактов, выделенных из культуральных жидкостей штаммов Bacillus subtilis BZR 336g (1) и BZR 517 (2) - перспективных продуцентов биофунгицидов. Использованы пластины с модифицированным силикагелем Kieselgel 60 («Merck», Германия); после хроматографического разделения метаболитов силикагель пропитывали картофельно-глюкозной питательной средой, суспензией пропагул гриба и помещали на 48-50 ч во влажную камеру.

Для выявления активных фракций метаболитов методом биоавтографии в качестве тест-объектов использовали фитопатогенные грибы F. oxysporum var. orthoceras BZRP1 и Alternaria sp. BZRP8, что позволило оценить антифунгальный эффект в отношении возбудителей корневых гнилей злаков и альтернариоза плодовых культур. Оба исследованных штамма синтезировали комплекс активных соединений с фунгистатическими и фунгицидными свойствами (табл.). При этом у штамма BZR 517 
обнаружили четыре наиболее выраженных зоны полного подавления роста гриба $F$. oxysporum var. orthoceras BZRP1, тогда как у BZR 336g - только две. Характер роста гриба также отличался от обычного вследствие фунгистатического эффекта метаболитных соединений (см. рис., Б). На биоавтограммах с грибом Alternaria sp. BZRP8 число зон метаболитов с фунгитоксичным влиянием значительно сократилось: у обоих штаммов было выявлено по две наиболее четкие зоны ингибирования гриба (табл.). Однако у BZR 517 проявление антигрибных свойств оказалось более выражено, чем у BZR 366g (см. рис., Б).

Подвижность, свечение в УФ 366 -свете и антифунгальные свойства компонентов этилацетатного экстракта культуральной жидкости, продуцируемых изученными штаммами Bacillus subtilis

\begin{tabular}{|c|c|c|c|c|}
\hline \multirow[b]{2}{*}{ Штамм } & \multirow[b]{2}{*}{ Rf зоны } & \multirow[b]{2}{*}{ Характер свечения } & \multicolumn{2}{|c|}{ Антигрибная активность } \\
\hline & & & $\begin{array}{l}\text { Fusarium oxysporum var. } \\
\text { Orthoceras BZRP1 }\end{array}$ & $\begin{array}{l}\text { Alternaria } \\
\text { sp. BZRP8 }\end{array}$ \\
\hline \multirow[t]{13}{*}{ B. subtilis BZR 336g } & 0,32 & Слабое серое & - & - \\
\hline & 0,39 & Голубовато серое & +++ & - \\
\hline & 0,42 & Голубовато-серое & + & ++ \\
\hline & 0,51 & Серо-голубое & - & - \\
\hline & 0,57 & Cepoe & - & - \\
\hline & 0,73 & Яркое белесое & + & - \\
\hline & 0,78 & Яркое зеленоватое & + & - \\
\hline & 0,81 & Синее & + & - \\
\hline & 0,84 & Светлое зеленоватое & - & - \\
\hline & 0,87 & Темно-зеленое & + & - \\
\hline & 0,91 & Яркое белесое & + & - \\
\hline & 0,94 & Яркое белесое & + & + \\
\hline & 0,96 & Темно-зеленое интенсивное & +++ & +++ \\
\hline \multirow[t]{10}{*}{ B. subtilis BZR 517} & 0,32 & Cepoe & - & - \\
\hline & 0,39 & Яркое светло-голубое & + & - \\
\hline & 0,42 & Cepoe & +++ & ++ \\
\hline & 0,48 & Светло-голубое & + & - \\
\hline & 0,56 & Светло-голубое & + & - \\
\hline & 0,67 & Cepoe & + & - \\
\hline & 0,75 & Яркое светло-голубое & + & - \\
\hline & 0,84 & Cepoe & ++ & - \\
\hline & 0,92 & Светло-голубое & +++ & + \\
\hline & 0,96 & Зеленовато-желтое & +++ & +++ \\
\hline $\begin{array}{l}\text { П р и м е ч а н и е. } \\
\text { фунгистатическая а } \\
\text { подавления роста г } \\
\text { ванным силикагелег }\end{array}$ & $\begin{array}{l}\text { нь проявл } \\
\text { ость, «+» } \\
\text { Разделень } \\
\text { lgel } 60 \text { (« }\end{array}$ & $\begin{array}{l}\text { яя активности: «+++»- фуні } \\
\text { слабая фунгистатическая акти } \\
\text { компонентов методом тонкосл } \\
\text { ck», Германия). }\end{array}$ & $\begin{array}{l}\text { ицидная активность, «++ } \\
\text { вность; прочерки означаґ } \\
\text { тойной хроматографии с }\end{array}$ & $\begin{array}{l}\text { - средняя } \\
\text { отсутствие } \\
\text { дифициро- }\end{array}$ \\
\hline
\end{tabular}

Опрыскивание пластины дистиллированной водой позволило выявить компоненты с гидрофобными свойствами (проявлялись как белые пятна): у штамма BZR 517 - зону с Rf 0,84, у BZR 336g - две зоны с Rf 0,75 и 0,84 . По мнению многих авторов, наличие поверхностно-активных метаболитов может усиливать антагонистические свойства бактерии за счет влияния на их способность быстро распространяться по листовой поверхности и в ризосфере (8).

С помощью детектирующих реагентов были обнаружены функциональные группы, которые могут способствовать появлению биологической активности метаболитов у исследованных штаммов. При опрыскивании свежеприготовленной смесью $0,1 \mathrm{M} \mathrm{FeCl}_{3}$ и $0,1 \mathrm{M}$ феррицианида калия (1:1) одна зона метаболитов у штамма BZR 517 (c Rf 0,92) и три зоны - у BZR 336g (c Rf 0,42; 0,57 и 0,73) окрашивались в ярко-синий цвет, что свидетельствовало о наличии активных соединений ароматических аминов, фенолов и фенольных стероидов. Темно-синее окрашивание зон раствором $\mathrm{Na}_{2} \mathrm{CO}_{3}$ и реактивом Фолина у штаммов BZR 517 и BZR 336g, вероятно, указывало на присутствие метилгидразинов и фенолкарбоновых кислот. С помощью $0,25 \%$ раствора нингидрина выявили присутствие 
свободных аминогрупп в одной зоне с Rf 0,73 у штамма BZR 336g (пятно желто-оранжевого цвета). Две зоны с Rf 0,42 и 0,73 у BZR 336g окрасились в темно-красный цвет $0,5 \%$ раствором соли «прочная красная В», что может свидетельствовать о наличии фенолов и оксибензофенонов (20).

По результатам исследования можно сделать некоторые предположения относительно характера действия антигрибных метаболитов у штаммов B. subtilis BZR 336g и BZR 517. Поскольку детектирующие реактивы указывают на наличие разнообразных фенольных производных, а активные штаммы при взаимодействии с фитопатогеном продуцируют гидролитические ферменты $(21,22)$, то одним из механизмов, посредством которого осуществляется подавление фитопатогенного микроорганизма, может быть гидролиз фенольных соединений. При этом освобождаются активные группы фенолов, что способствует усилению антигрибной активности синтезируемых метаболитов. Так как попытка осадить исследуемые метаболиты подкислением либо сульфатом аммония не увенчалась успехом, мы предполагаем, что большинство из них имеют непептидную структуру. Есть сведения, что некоторые штаммы $B$. subtilis образуют полиеновые антибиотики с конъюгированными двойными связями, способные ингибировать рост фитопатогенных грибов (23). Спектрофотометрическое исследование активных фракций метаболитов у штаммов B. subtilis BZR 336g и BZR 517 показало, что оба штамма продуцировали соединения с максимумом поглощения при $\lambda=205-217$ нм, что служит косвенным доказательством наличия коротких полиеновых цепей в структуре изучаемых веществ. У длинных полиеновых цепей полосы поглощения попадают в видимую область, то есть соединение становится окрашенным (Rf 0,96) (24).

Многими авторами показано, что усиленная продукция активных метаболитов способствует увеличению антагонистической активности штаммов B. subtilis, отобранных в качестве перспективных биофунгицидных агентов. Выявлено, что при болезни хлопчатника, вызванной Rhizoctonia solani, антигрибной эффект штамма B. subtilis NCD-2 в отношении патогена связан главным образом с липопептидами фенгицинового ряда (25). На листьях дыни ключевую роль в антагонизме четырех штаммов $B$. subtilis по отношению к возбудителю болезни Podophaera fusca играли липопептиды семейств итуринов и фенгицинов (26). Фенгицины, синтезируемые B. subtilis, имели основное значение в защите бобовых растений от Pythium ultimum $(27,28)$. Штамм B. subtilis CMB32 синтезирует липопептиды, ответственные за антифунгальную активность против Colletotrichum gloeosporioides, вызывающего у растений антракноз (29). У изученных нами штаммов антигрибные метаболиты, в отличие от известных липопептидов (30), по-видимому, имеют непептидную природу.

Таким образом, штаммы Bacillus subtilis BZR 336g и BZR 517 синтезируют значительное количество фунгитоксичных метаболитов. Тонкослойная хроматография, биоавтография, детектирование проявляющими реактивами и методы оптической спектроскопии позволили нам получить данные, прямо или косвенно характеризующие свойства и структуру биоактивных соединений, продуцируемых исследованными штаммами. Их перспективность заключается в способности синтезировать большой набор антигрибных метаболитов, в том числе, вероятно, непептидных соединений. Полученные результаты подтверждают высокий потенциал штаммов B. subtilis BZR 336g и BZR 517 при их использовании для разработки средств защиты от фитопатогенных грибов. 


\section{ЛИТЕРАТУРА}

1. Wang T., Liang Y., Wu M., Chen Z., Lin J., Yang L. Natural products from Bacillus subtilis with antimicrobial properties. Chinese J. Chem. Eng., 2015, 23 (I4): 744-754 (doi: 10.1016/j.cjche.2014.05.020).

2. Yang H., Li X., Li X., Yu H., Shen Z. Identification of lipopeptide isoforms by MALDI-TOFMS/MS based on the simultaneous purification of iturin, fengycin and surfactin by RP-HPLC. Anal. Bioanal. Chem., 2015, 407(9): 2529-2542 (doi: 10.1007/s00216-015-8486-8).

3. Jacobsen B., Zidack N., Larson R. Bacillus isolates and methods of their use to protect against plant pathogens. US Patent № 8246965 A 61 K 39/07 C 12 2012, №1/20.

4. Stein T. Bacillus subtilis antibiotics: structures, syntheses and specific functions. Mol. Microbiol., 2005, 56(4): 845-857 (doi: 10.1111/j.1365-2958.2005.04587.x).

5. Сидорова Т.М., Асатурова А.М., Хомяк А.И. Биологически активные метаболиты Bacillus subtilis и их роль в контроле фитопатогенных микроорганизмов (обзор). Сельскохозяйственная биология, 2018, 53(1): 29-37(doi: 10.15389/agrobiology.2018.1.29rus).

6. Debois D., Fernandez O., Franzil L., Jourdan E., de Brogniez A., Willems L., Clement C., Dorey S., De Pauw E., Ongena M. Plant polysaccharides initiate underground crosstalk with bacilli by inducing synthesis of the immunogenic lipopeptide surfactin. Env. Microbiol. Rep., 2015, 7(3): 570-582 (doi: 10.1111/1758-2229.12286).

7. Falardeau J., Wise C., Novitsky L., Avis T.J. Ecological and mechanistic insights into the direct and indirect antimicrobial properties of Bacillus subtilis lipopeptides on plant pathogens. $J$. Chem. Ecol., 2013, 39(7): 869-878 (doi: 10.1007/s10886-013-0319-7).

8. Alonso S., Martin P.J. Impact of foaming on surfactin production by Bacillus subtilis: implications on the development of integrated in situ foam fractionation removal systems. Biochem. Eng. J., 2016, 110: 125-133 (doi: 10.1016/j.bej.2016.02.006).

9. Shafi J., Tian H., Ji M. Bacillus species as versatile weapons for plant pathogens: a review. Biotechnology \& Biotechnological Equipment, 2017, 31(3): 446-459 (doi: 10.1080/13102818.2017.1286950).

10. Sirec T., Cangiano G., Baccigalupi L., Ricca E., Isticato R. The spore surface of intestinal isolates of Bacillus subtilis. FEMS Microbiology Letters, 2014, 358(2): 1-8 (doi: 10.1111/15746968.12538).

11. Новикова И.И., Бойкова И.В., Павлюшин В.А., Зейрук В.Н., Васильева С.В., Азизбекян Р.Р., Кузнецова Н.И. Перспективы использования биопрепаратов на основе микробов-антагонистов для защиты картофеля от болезней при хранении. Вестник защиты растений, 2013, 4: 12-21.

12. Тютерев С.Л. Экологически безопасные индукторы устойчивости растений к болезням и физиологическим стрессам. Вестник защиты растений, 2015, 1(83): 3-13.

13. Raaijmakers J.M., de Bruijn L., Nybroe O., Ongena M. Natural functions of lipopeptides from Bacillus and Pseudomonas: more than surfactants and antibiotics. FEMS Microbiol. Rev., 2010, 34: 1037-1062 (doi: 10.1111/j.1574-6976.2010.00221.x),

14. Chowdhury S.P., Hartmann A., Geo X.W., Borriss R. Biocontrol mechanism by root-associated Bacillus amyloliquefaciens FZB42 - a review. Front. Microbiol., 2015, 6: Article 780 (doi: 10.3389/fmicb.2015.00780).

15. Асатурова А.М., Дубяга В.М. Штамм бактерий Bacillus subtilis для получения биопрепарата против фитопатогенных грибов. Патент на изобретение № 2553518. Опубл. 20.06.2015. Бюл. № 17.

16. Асатурова А.М., Дубяга В.М. Штамм бактерий Bacillus subtilis BZR 517 для получения биопрепарата против фитопатогенных грибов. Патент на изобретение № 2552146. Опубл. 10.06.2015. Бюл. № 16.

17. Асатурова А.М., Дубяга В.М., Томашевич Н.С., Жарникова М.Д. Отбор перспективных агентов биологического контроля для защиты озимой пшеницы от возбудителей фузариоза. Электронный политематический научный журнал КубГАУ, 2012, 75(01). Режим доступа: http://ej.kubagro.ru/2012/01/pdf/37.pdf. Без даты.

18. Чигрин В.В., Розум Л.В., Сидорова Т.М. Способ обнаружения физиологически активных веществ растительного происхождения. A. c. SU 1824146A1 A 01 N 61/00 G 01 N 30/90 № 1824146. Заявл. 11.01.91. Опубл. 30.06 .93 г. Бюл. № 24.

19. Кирхнер Ю. Тонкослойная хроматография. Т. 1. М., 1981: 221-285.

20. Zhang B., Dong C., Shang Q., Han Y., Li P. New insighs into membrane-active action in plasma membrane of fungal hyphae by the lipopeptide antibiotic bacillomycin L. $B B A$ Biomembranes, 2013, 1828(9): 2230-2237 (doi: 10.1016/j.bbamem.2013.05.033).

21. Wise C., Falardeau J., Hagberg I., Avis T. Cellular lipid composition affects sensitivity of plant pathogens to fengycin, an antifungal compound produced by Bacillus subtilis strain CU12. Phytopathology, 2014, 104(10): 1036-1041 (doi: 10.1094/PHYTO-12-13-0336-R).

22. Santos A., Mendes S., Brissos V., Martins L.O. New dye-decolorizing peroxidases from Bacillus subtilis and Pseudomonas putida MET94: towards biotechnological applications. Appl. Microbiol. Biotechnol., 2014, 98: 2053 (doi: 10.1007/s00253-013-5041-4).

23. Guo Q., Dong W., Li S., Li X., Wang P., Zhang X., Wang Y., Ma P. Fengycin produced by 
Bacillus subtilis NCD-2 plays a major role in biocontrol of cotton seedling damping-off disease. Microbiol. Res., 2014, 169(7-8): 533-540 (doi: 10.1016/j.micres.2013.12.001).

24. Romero D. The iturin and fengycin families of lipopeptides are key factors in antagonism of Bacillus subtilis toward Podosphaera fusca. MPMI, 2007, 20(4): 430-440 (doi: 10.1094/MPMI20-4-0430).

25. Ongena M., Jacques P., Toure Y., Destan J., Jabrane A., Thonart P. Involvement of fengycintype lipopeptides in the multifaceted biocontrol potential of Bacillus subtilis. App. Microbiol. Biotechnol., 2005, 69(1): 29-38 (doi: 10.1007/s00253-005-1940-3).

26. Falardeau J., Wise C., Novitsky L., Avis T.J. Ecological and mechanistic insights into the direct and indirect antimicrobial properties of Bacillus subtilis lipopeptides on plant pathogens. $J$. Chem. Ecol., 2013, 39(7): 869-878 (doi: 10.1007/s10886-013-0319-7).

27. Kudryashova E.B., Vinokurova N.G., Arishina E.V. Bacillus subtilis and phenotypically similar strains producing hexaene antibiotics. Applied Biochemistry and Microbiology, 2005, 41: 553-557 (doi: 10.1007/s10438-005-0087-4).

28. Маланичева И.А., Козлов Д.Г., Ефименко Т.А., Зенкова В.А., Катруха Г.С., Резникова М.И., Королев А.М., Борщевская Л.Н., Тарасова О.Д., Синеокий С.П., Ефременкова О.В. Новые антибиотики, образуемые штаммами Bacillus subtilis. Микробиология, 2014, 83(4): 445-450.

29. Kim P.I., Ryu J., Kim Y.H., Chi Y.-T. Production of biosurfactant lipopeptides iturin A, fengycin and surfactin A from Bacillus subtilis CMB32 for control of Colletotrichum gloeosporioides. J. Microbiol. Biotechnol., 2010, 20(1): 138-145 (doi: 10.4014/jmb.0905.05007.

30. Pirog T.P., Konon A.D., Savenko I.V. Microbial surfactants in environmental technologies. Biotechnologia Acta, 2015, 8(4): 21-39 (doi: 10.15407/biotech8.04.021).

\title{
ФГБНУ Всероссийский НИИ биологической
} защиты растений,

350039 Россия, г. Краснодар, п/о 39,

e-mail: 0166505@mail.ru $\bowtie$, biocontrol-vniibzr@yandex.ru,

HomyakAI87@mail.ru, tom-s2@yandex.ru

Sel'skokhozyaistvennaya biologiya [Agricultural Biology], 2019, V. 54, № 1, pp. 178-185

\section{ISOLATION AND CHARACTERIZATION OF ANTIFUNGAL METABOLITES OF Bacillus subtilis STRAINS BZR 336G AND BZR 517 USING THE MODIFIED BIOAUTHOGRAPHY METHOD}

\author{
T.M. Sidorova, A.M. Asaturova, A.I. Homyak, N.S. Tomashevich
}

All-Russian Research Institute of Biological Plant Protection, PO box 39, Krasnodar, 350039 Russia, e-mail 0166505@mail.ru ( $₫$ corresponding author), biocontrol-vniibzr@yandex.ru, HomyakAI87@mail.ru, tom-s2@yandex.ru ORCID:

Sidorova T.M. orcid.org/0000-0003-4281-5278

Asaturova A.M. orcid.org/0000-0002-0060-1995

Homyak A.I. orcid.org/0000-0001-9360-2323

The authors declare no conflict of interests

Acknowledgements:

Tomashevich N.S. orcid.org/0000-0002-7297-5929

This work was performed according to the state assignment No. 075-00376-19-00 of the Ministry of Science and Higher Education of the Russian Federation within the framework of the research on subject No. 06862019-0013.

Received October 17, 2017

doi: 10.15389/agrobiology.2019.1.178eng

\section{Abstract}

The ability of $B$. subtilis to produce a large number of biologically active metabolites of diverse structure and properties can largely determine its fungicidal effect against particularly dangerous pathogenic fungi. In this regard, we have studied the fungicidal activity and properties of the antifungal metabolites of active strains $B$. subtilis BZR 336g and BZR 517. The approach we used, including purification by extraction with ethyl acetate, thin-layer chromatography (TLC), UV fluorescence, tests with detection reagents, spectroscopy and bioautography, showed the potential of the studied B. subtilis strains to accumulate the complex of active metabolites exhibiting antifungal effect from fungistatic to fungicidal. Bioautographic method was modified by use of the causative agents of harmful diseases, F. oxysporum var. orthoceras and Alternaria sp. as test organisms, which allowed us to assess in vitro the antifungal activity. Patterns of the antifungal compounds differed between the strains in TLC mobility and UV fluorescence. The impact on fungal growth also differed, from slight changes in mycelium growth to total suppression. In strain B. subtilis BZR 336g the most pronounced inhibition of $F$. oksysporum var. orthoceras BZRP1 growth was in bands with Rf 0.39 and 0.96. Significant Alternaria sp. BZRP8 growth inhibition was also observed in two bands, with Rf 0.42 and 0.96 . B. subtilis BZR 517 synthesizes metabolites exhibiting fungitoxic properties in four 
bands with $\mathrm{Rf} 0.42,0.84$. 0.92 and 0.96 against $F$. oxysporum var. orthoceras BZRP1, and in two bands with Rf 0.42 and 0.96 against Alternaria sp. BZRP8. It is known that, in addition to the direct action, surfactins and fengicins of $B$. subtilis prevent the adhesion of competitive microbes on the plant. In out tests, spraying TLC plates with distilled water revealed bands with hydrophobic properties (non-wetting white zones), which can enhance the antagonistic effect of $B$. subtilis. Test with detection reagents visualized the presence of aromatic amines, phenols, phenolic steroids, methyl hydrazines, that is, compounds that probably play a certain role in the bioactivity manifestation. The weak staining of the metabolites with ninhydrin, as well as the absence of characteristic precipitation during acidification of the culture medium or adding ammonium sulfate, may indicate the presence of only minor amounts of amino acids and peptides. Spectrophotometrically we detected absorption peaks at 205-217 nm wavelengths, which indirectly evidences the presence of polyene structures. Our data allow us to hypothesize mechanisms underlying antifungal effects in the studied $B$. subtilis strains. These effects may be due to hydrolysis of phenolic compounds, since the detecting reagents indicate various phenolic derivatives, and, according to many researchers' opinion, active strains, when interacting with a phytopathogen, produce hydrolytic enzymes. As a result, the active groups of phenols can be released, which enhances the antifungal activity of the synthesized metabolites via effect on both fungal cell walls and other cell structures.

Keywords: Bacillus subtilis, microbiological preparations, antifungal metabolites, fungitoxicity, thin-layer chromatography, bioautography, detection reagents, phenolic compounds, polyene structures.

\title{
Научные собрания \\ 11-Я МЕЖДУНАРОДНАЯ ШКОЛА МОЛОДЫХ УЧЕНЫХ «СИСТЕМНАЯ БИОЛОГИЯ И БИОИНФОРМАТИКА», SВВ-2019» (11th INTERNATIONAL YOUNG SCIENTISTS SCHOOL «SYSTEMS BIOLOGY AND BIOINFORMATICS», SBB-2019)
}

(24-28 июня 2019 года, Институт цитологии и генетики СО РАН, г. Новосибирск, Россия)

\begin{abstract}
Системная биология - междисциплинарное направление, включающее в себя различные методы экспериментального и компьютерного изучения закономерностей организации и функционирования между составляющими биологических систем всех уровней. Мероприятия из цикла «Международная школа молодых ученых “Биоинформатика и системная биология” были актуальные на момент организации мероприятия вопросы.

Основные направления Школы SBB-2019:

- геномика и транскриптомика

- эволюционная биология

- структурная биология и молекулярная динамика

- анализ молекулярно-генетических систем

- генетика, геномика, биоинформатика и биотехнология растений

- биомедицина
\end{abstract} составлены согласно уровню знаний студентов и молодых ученых, а также освещали самые

\section{Программа Школы включает:}

- полноценные часовые лекции ведущих специалистов;

- практические занятия;

- сообщения молодых ученых с конкурсом лучших работ и оценкой каждого выступления, а также постерные сессии

Практические занятия - это особенность школ серии SBB. Они будут проходить в минигруппах студентов под руководством приглашенных лекторов по заданным ими тематикам с выполнением практических компьютерных занятий и конкурсной оценкой работ. Продолжительность практического занятия -8 часов. Практические занятия пройдут в два дня.

Одновременно со Школой SBB-2019 в ИЦиГ СО РАН пройдет 5-я Международная научная конференция «Генетика, геномика, биоинформатика и биотехнология растений» (PlantGen2019, 24-29 июня 2019 года, г. Новосибирск, Россия), где будут представлены результаты новейших исследований в области генетики, геномики, биоинформатики и биотехнологии растений, а также планируется обсуждение перспективных направлений исследований (в том числе совместных) по фундаментальным и прикладным аспектам изучения генома растений.

Контакты и информация: http://conf.bionet.nsc.ru/sbb2019/ 